Hence there are two basic principles of patent law, (a) that patents are granted in consideration of the disclosure of inventions ; (b) that they are granted for the institution of new industries.

Although both principles may fitly be recognised in a given system of patent law, they cannot be regarded as coequal. For the type of administration appropriate to (a) not only differs from, but also is even antagonistic to, that which would naturally be evolved under $(b)$. Under $(a)$ there must be a highly elaborated machinery for the investigation of novelty, with the result that patents will be granted with relatively narrow claims, and that the capitalist be able to buy inventions cheaply, for patents will possess little restraining power. An official search, no doubt, gives additional security, but the commercially valuable factor in a monopoly is its restraining power. Hence, as a general rule, when security is at its highest the other factor will be " little, or none at all."

Trustworthy evidence of the commercial value of patents is not readily obtainable-for it is against the interest of patent officials, agents and owners alike publicly to depreciate their own services or properties. The following communication, however, was sent to the present writer in I923 from a well-known scientific writer in Washington. He writes: "I have been wondering for some time whether the world's patent offices are not about to break down under their own weight. Simple arithmetic shows that the possible permutations and combinations of known principles and kinds of matter are so numerous that their task is hopeless unless the definition of invention or originality is radically changed. The U.S. Patent Office is already in a badly demoralised state and far behind with its applications, and its patents have for some years been recognised as worthless in themselves, being essen tially only tickets of admission to the courts of law." Corroborative evidence on this point will be found in my letter to NATURE, Nov. II, I922, p. 633 These are inside views of the effect of a universal search upon the selling value of patents.

The writer of the articles in NATURE of July 25 and August I proposes a search through the I759 periodicals taken in the Patent Office Library. But what about the 24,028 registered in the recently published "World List of Scientific Periodicals"? His search is to be limited to suit the convenience and capacities of the examining staff. Section $4^{\circ}$ (I) of the Patents and Designs Act 1907 established the principle that "what we don't know isn't knowledge" in -order to round off the official 50-year search (see my letter as above). When I pointed this clause out to a legal authority, he said it was "damned nonsense" -but it is proposed in the articles referred to above to extend the principle.

The remedy is obvious. An administrative search for novelty has long been an econornic absurdity. The direction in which reform should be sought, if the object of our patent law is to stimulate the growth of British industries, is in the relief of the patentee from the unduly high legal standard of novelty. Sir John Dewrance in his presidential address before the Institution of Mechanical Engineers in I923 supports this contention. He writes: "It has always seemed to me to be unfair that documents should be evidence of anticipation : evidence should be of prior use." This relief can, of course, be granted to the patentee only upon proof of commercial working.

Hence official search for novelty should be restricted to secure that concurrent British patents are not granted with overlapping claims. With a simplified procedure and broader claims, which can be substantiated so soon as the patented process has been reduced to practice, capital will once more flow into native industries.

Underlying the case presented in NATURE is the thesis that the public requires to be protected against the inventor. My case is that the inventor should be wooed and if possible won to come over and help us, and for this purpose I would make the law clear and consistent and the official practice cheap and expeditious. E. Wyndham Hulme.

\section{A Radio Method of Estimating the Height of the Conducting Layer.}

Is a recent note we have outlined a method of estimating the height of the conducting layer by means of radio waves (M. A. Tuve and G. Breit, Terv. Mag., vol. 30 (1925), pp. I5-I6). Through the co-operation of the U.S. Naval Research Laboratory, Bellevue, Anacostia, D.C., we have obtained definite indications of reflections such as would take place from the layer and some estimates of its height. The method used consists in sending out interrupted high frequency wave-trains and observing the wave-form of the received signal. Each wave-train received manifests itself as a temporary rise in the detector current of the receiving set. One particular wavetrain at the transmitter gives rise to two received wave-trains at the receiver if a single reflection takes place. One of these trains travels over the ground and the other by way of the layer. Thus the detector current is forced to rise at two different times by the same wave-train from the transmitter and an oscillogram of the detector current shows two humps generally of unequal size.

The transmitter was operated with a 500-cycle plate current supply so that a wave-train of $7 \mathrm{I} \cdot 3$ metres wave-length was emitted during a part of each positive half of the cycle. A succession of single humps is thus emitted. (We have made sure of this by observing the wave form at the same time at the transmitting and the receiving stations.) The receiving station was located 7 miles away from the transmitter in a general direction north, the Potomac River and the City of Washington being between the two stations. We have observed the received waveform visually and photographically. Double and triple humps were observed on some days, though practically single humps were observed on others. Marked variations in the relative position and amplitude of the humps were observed during ro-minute observation periods. The retardation of the secondary humps with respect to the primary is of the order of I/ 1700 second, which corresponds to a retardation over a length of roughly i 10 miles and a distance of the layer of the order of 50 miles. Other humps correspond to roo miles. The origin of triple humps is not clear. The possibilities of a wavy surface in the layer and successive reflections suggest themselves.

Experiments on other wave-lengths with different receivers and transmitters and in different locations seem valuable. We are hoping that such experiments will be performed by others as well as ourselves. Some experiments at 600 metres were performed in co-operation with the Radio Corporation of America, the distances between the two stations being about I 50 and IoO miles. No definite indication of the presence of the layer was found in these cases.

G. BREIT.

M. A. Tuve.

Department of Terrestrial Magnetism,

Carnegie Institution of Washington, Washington, D.C.

NO. 29 I 4 , VOL. I I 6$]$ 